\title{
O TRABALHO DE INCLUSÃO ESCOLAR À PROVA DAS SINGULARIDADES DOS ALUNOS Formas, condições e limites do reconhecimento da vulnerabilidade nas escolas
}

\section{THE WORK OF SCHOOL INCLUSION PUT TO THE TEST OF STUDENTS' SINGULARITIES \\ Forms, conditions and limits of the recognition of vulnerability in schools}

\author{
João Feijão \\ Universidade NOVA de Lisboa, Faculdade de Ciências Sociais e Humanas, Centro Interdisciplinar de Ciências \\ Sociais (CICS.NOVA). Avenida de Berna, 26C, 1069-061 Lisboa, Portugal. Email: joaomfeijao@gmail.com
}

\section{Nélia Freitas}

Universidade NOVA de Lisboa, Faculdade de Ciências Sociais e Humanas (NOVA FCSH). Avenida de Berna, 26C, 1069-061 Lisboa, Portugal. Email: neliafreitas@live.com.pt

\begin{abstract}
Resumo: Este texto visa apresentar reflexões sobre a forma como se faz, desfaz e refaz o reconhecimento e a inclusão dos seres mais vulneráveis que habitam o mundo escolar. Interrogamo-nos sobre o que é que a escola faz aos alunos com necessidades educativas especiais, sobretudo aqueles com Perturbação de Hiperatividade e Défice de Atenção. Com recurso a entrevistas junto de profissionais educativos encontrámos quatro formas de trabalhar os alunos com PHDA que coexistem na escola e que introduzem uma experiência ambivalente entre a normalização das diferenças e o reconhecimento da singularidade destes alunos.
\end{abstract}

Palavras-chave: reconhecimento, inclusão, vulnerabilidade, escola.

\begin{abstract}
This text aims to present reflections on a way in which the recognition and the inclusion of the most vulnerable beings that inhabit the school world is done, undone and redone. We wonder what the school is doing with the special need education students, especially those with Attention Deficit and Hyperactivity Disorder. Recurring to the interviews with educational professionals we found four forms of working with ADHD students that introduce an ambivalent experience between the exclusion and normalization of differences and the recognition of students' singularities.
\end{abstract}

Keywords: recognition, inclusion, vulnerability, school.

\section{Introdução: o reconhecimento das singularidades e vulnerabilidades dos seres que habitam o mundo escolar}

As reflexões que se apresentam alicerçam-se num programa de investigação comum: compreender de que forma se faz, desfaz e refaz o reconhecimento dos seres mais vulneráveis que habitam o mundo escolar, sobretudo quais as formas, as condições e os limites do seu reconhecimento. ${ }^{1}$ 
Trata-se de uma linha de investigação em crescente expansão que sido desenvolvida, por investigadores a nível internacional (Breviglieri, 2009; Dubet, 2004; Dubet et al., 2013; Giuliani et al., 2008; Honneth, 2005; Laforgue, 2009; Pattaroni, 2007; Payet, 2006; Payet et al., 2008), mas também a nível nacional (Dionísio, Resende \& Caetano, 2014; Feijão \& Freitas, 2014; Resende \& Gouveia, 2013).

O desenvolvimento desta sociologia moral e pragmática do reconhecimento (Payet et al., 2008) tem permitido pensar, por um lado, a forma como diferentes seres são qualificados e desqualificados pelas diferentes instituições com as quais desenvolvem uma relação social (trabalho social, escola, justiça, etc.) e portanto a forma como essas instituições reconhecem, ou não, esses seres como pessoas com uma subjetividade própria (Pattaroni, 2007), tornando mais ou menos visível a sua presença (Honneth, 2005). Por outro lado, não têm sido raros os estudos que se têm centrado sobre os próprios seres vulneráveis, indagando sobre a sua autonomia, a capacidade de fazerem ouvir a sua voz e expressarem os seus sentimentos de injustiça, de desprezo e de discriminação de que consideram ser alvo por parte das diferentes instituições (Dionísio, Resende \& Caetano, 2014; Dubet et al., 2013; Payet et al., 2008).

Não é inocente a forma como se invoca esta capacidade crítica dos atores de se pronunciarem acerca daquilo que consideram ser justo ou injusto nas situações que experienciam quotidianamente. Nesta linha tem-se mostrado profícua a mobilização da sociologia dos regimes de justificação e de envolvimento, também conhecida como sociologia pragmática, que tende a conceber os atores como competentes, isto é, capazes de emitir pontos de vista críticos em relação a essas situações, engendrando novas formas de se envolverem e produzirem o comum (Boltanski \& Thévenot, 1991; Thévenot, 2006).

A crítica às injustiças escolares tem sido objeto de profunda reflexão entre cientistas sociais que se dedicam ao estudo do campo educativo. Com efeito, apesar da democratização do acesso à escola, que se traduziu na adesão de uma moldura estudantil heterogénea do ponto de vista da sua composição social e cultural, esta não se fez acompanhar por uma democratização relativa, sendo considerado que estamos perante uma democratização segregadora (Dubet, 2003; 2007). Neste debate sobre aquilo que é uma escola justa (Dubet, 2004) as críticas mais ferozes são disferidas ao paradigma da igualdade de oportunidades. Apesar da escola se desresponsabilizar da produção e reprodução das desigualdades, a questão é que o modelo da igualdade de oportunidades, assente no mérito de cada um, pressupõe que todos estão envolvidos na mesma competição, ignorando as diferenças de base dos alunos, respeitantes à sua condição social e cultural, o que os impede de competir e deixa-os em relativa desvantagem (Bourdieu \& Champagne, 1992). 
A escola republicana estava protegida contra os excluídos. Os vencidos pela competição escolar, findada a escolaridade obrigatória, abandonavam a escola e alguns deles abandonavam-na antes disso (Bourdieu \& Champagne, 1992; Dubet, 2004). A escola era um lugar violento para esta fração da população escolar, exercendo sobre ela uma violência não só simbólica, mas também uma violência física que os fazia a levar a pensar que não tinham lugar na escola (Dubet, 2002). Pelo contrário, a escola contemporânea transporta consigo o slogan da inclusão escolar (Sanches \& Teodoro, 2006), sendo obrigatória para todos, obrigada a acolher todos e tendo em conta as singularidades de cada aluno como pessoa.

Este slogan da inclusão escolar tem expressão visível nos mais variados programas compensatórios de educação, que se dirigem a grupos da população escolar mais vulneráveis e que geram debates sobre as formas de justiça que produzem e as gramáticas nas quais se ancoram (Dubet, 2004; Feijão, 2015).

Os excluídos são agora mantidos no interior da escola e os mecanismos de exclusão são mais subtis (Dubet, 2003). Embora com as novas abordagens pedagógicas mais humanistas, defensoras dos direitos das crianças e do seu tratamento como seres com dignidade, deixe de ser legítimo o uso da violência física sobre os corpos dos alunos (Dionísio, Resende \& Caetano, 2014; Feijão \& Freitas, 2014), continua a imperar uma violência simbólica que sela cada vez mais precocemente os destinos escolares dos alunos, empurrando-os para fileiras menos prestigiadas do ponto de vista escolar (Bourdieu \& Champagne, 1992) e que têm sido denunciados pelos próprios alunos que se sentem humilhados, desprezados e maltratados (Dionísio, Resende \& Caetano, 2014; Dubet et al., 2013).

Todos estes aspetos levam a que Dubet (2004) defenda que é difícil definir os conceitos de justiça e de igualdade escolar dado que são conceitos pouco claros e isso faz com que a definição de uma escola justa seja complexa e ambígua, já que a justiça se pode definir sobre uma pluralidade de formas, dependendo das situações e do julgamento dos atores envolvidos nessas situações.

É este o cenário de complexidade do contexto escolar, em que a escola é obrigada a reconfigurar o seu programa institucional (Dubet, 2002) face à sua população escolar heterogénea e portadora de uma pluralidade de sentidos de justiça escolar, que os professores enfrentam a dificuldade de compor o comum face às singularidades de cada aluno como pessoa. Na nova forma escolar moderna, trabalhar o outro implica conceber a existência de um continuum entre as figuras do aluno, do jovem, da criança e do adolescente. Os professores vêm-se na obrigação de conciliar estes vários investimentos de forma (Thévenot, 2006), isto é, não só lidar com a figura institucional do aluno, mas ter também as competências relacionais necessárias para saber lidar igualmente com outras figuras também presentes na 
escola e fazer o difícil trabalho de emancipá-las enquanto pessoas e integrá-las na ordem comum, realizando a proximidade ao jovem, ao adolescente e à criança, mas sem colonizar a sua intimidade (Breviglieri, 2009; Pattaroni, 2007).

Os professores são, portanto, desafiados a sair daquela que era até então a sua esfera de atuação privilegiada, o domínio do pedagógico, e a desenvolverem novas competências relacionais com o intuito de melhorem a sua relação com o outro dentro da sala de aula, um lugar que perdeu o seu estatuto de santuário e onde a autoridade dos professores não é mais dada como natural, tornando a relação pedagógica frágil e obrigando a processo de reconstrução diária (Barrère, 2005; Dubet, 2002). Para coadjuvar os professores nesta sua nova missão, são trazidos para a escola um conjunto de técnicos especializados (psicólogos escolares, assistentes sociais, animadores, mediadores, técnicos de saúde...) destinados à função de reparação dos handicaps cognitivos, sociais e físicos dos alunos, surgindo novas áreas e dispositivos dentro da escola como gabinetes de apoio aos alunos e às famílias, serviços de psicologia e orientação, gabinetes de mediação de conflitos, departamentos de educação especial, entre outros (Feijão \& Freitas, 2014; Millet \& Thin, 2003).

É preciso então compreender como é que estes dispositivos e profissionais diversos vão acolher e reparar as situações de vulnerabilidade em que se encontram os alunos. $\mathrm{O}$ nosso artigo tem como objeto de estudo a pluralidade de formas de trabalhar e reconhecer o outro vulnerável na escola, centrando-se numa categoria específica de alunos: aqueles que são portadores de Perturbação de Hiperatividade e Défice de Atenção (PHDA).

\section{A inclusão escolar dos alunos com necessidades educativas especiais: o caso dos alunos com hiperatividade e défice de atenção}

Segundo a Associação Portuguesa da Criança Hiperativa (s/d) é estimado que 3\% a $7 \%$ das crianças sejam afetadas com esta perturbação, existindo em cerca de 35 a 50 mil crianças e sendo mais comum o seu desenvolvimento nos rapazes.

De acordo com Maria Isabel Lourenço (2009), esta perturbação pode ser definida como um distúrbio de desenvolvimento caracterizado pela excessiva desatenção, excesso de atividade psicomotora e impulsividade, sendo que para ser diagnosticada a perturbação tem de estar presente de forma persistente e perturbadora em pelo menos seis de dezoito sintomas, sendo que metade corresponde aos distúrbios já descritos. Existem três diagnósticos possíveis, sendo o primeiro de Tipo Misto, que inclui simultaneamente agitação psicomotora e desatenção; um segundo tipo designado como Predominantemente Desatento, mais difícil de diagnosticar e onde prevalece o défice de atenção; e um terceiro tipo designado como 
Impulsivo, onde a agitação psicomotora é o indicador prevalente (Costa et al., 2010).

A controvérsia gerada em torno desta perturbação está relacionada não só com a sua origem desconhecida, mas também a forma como ela é regulada, o que gera um debate forte entre a comunidade científica e a comunidade educativa sobre a exclusiva administração de fármacos, a adoção de terapias comportamentais e cognitivas ou execução de ambas as metodologias de intervenção (Feijão \& Freitas, 2014).

No século XIX, a PHDA era confundida com estados de deficiência mental, psicoses, esquizofrenias e outros sintomas de perturbação mental, tanto mais que faziam parte das populações que, desde o século XVI, estavam albergadas nos hospitais psiquiátricos e hospícios com o objetivo de serem isolados da restante sociedade (Aranha, 2008). Apenas a partir dos anos '70, do século XX, se cunha o conceito de necessidades educativas especiais, sobretudo definindo critérios peda-

gógicos na diferenciação destas populações, e não apenas critérios exclusivamente médicos (Sanches \& Teodoro, 2006).

O Ensino Especial aparece em Portugal em meados do século XIX com a criação de várias instituições por todo o país, mas apenas em 1916, se criou uma especialização para professores destinados a apoiar crianças com dificuldades auditivas (Pereira, 2008). Em 1946, a educação especial chega à escola primária, sendo que nos anos ‘60, se estende às crianças invisuais e nos anos '70 engloba crianças com outros handicaps (Pereira, 2008). É igualmente em 1970 que é assumido o setor da Educação Especial, pelo Ministério da Educação, criando-se Equipas de Educação Especial Integrada nas escolas, destinadas a apoiar os alunos com necessidades educativas especiais (Pereira, 2008). A medida tomada em 2008 é também relevante, na medida em que consagra o reconhecimento a estes serviços especializados de educação, permitindo às escolas introduzirem alterações nos seus programas que permitam melhor integrar as crianças e jovens com necessidades educativas especiais.

\section{Metodologia}

Foi realizado um estudo qualitativo em dois agrupamentos de escolas, onde foram efetuadas treze entrevistas semi-diretivas, das quais seis a professores de ensino regular, cinco a professores de ensino especial e duas a profissionais especializados na área da saúde a exercerem funções nesses agrupamentos de escolas, nomeadamente a uma terapeuta psicomotricista e a uma psicóloga clínica.

Na seleção dos profissionais educativos a serem entrevistados procurou-se aqueles que no seu quotidiano tinham um contacto direto e mais frequente com 
alunos com necessidades educativas especiais, nomeadamente com alunos com Perturbação de Hiperatividade e Défice de Atenção. O convite à participação dos profissionais no estudo foi realizado pelas direções de cada agrupamento de escola.

A impossibilidade de recolher dados a um nível mais extenso em termos da participação de profissionais educativos deveu-se por um lado, à escassez de recursos humanos alocados às escolas para trabalhar com alunos com necessidades educativas especiais (professores de ensino especial e técnicos especializados), e por outro lado, à invocação de recusas à participação quer por falta de interesse ou de disponibilidade de tempo, quer pela necessidade de respeitar o dever de sigilo profissional ou ainda de não querer expor o seu trabalho quotidiano. Em relação a este último aspeto é de destacar a impossibilidade de podermos fazer qualquer tipo de observação aos quotidianos dos profissionais educativos que aceitaram participar neste estudo.

Sendo assim, a entrevista surge como a forma mais eficaz de podermos reconstruir os quotidianos de trabalho dos diferentes profissionais educativos, principalmente sobre forma como atuam face às situações com que confrontados e sobre o que encontram como impulsionador ou como limitador da sua ação junto dos alunos com Perturbação de Hiperatividade e Défice de Atenção.

O desenho do guião da entrevista foi pensado em torno de alguns temas como a conceção que os profissionais tinham das políticas educativas em torno do ensino especial, da forma como era feita a sinalização de alunos com PHDA, das estratégias de trabalho com estes alunos e outros membros da comunidade educativa (professores do ensino regular ou especial, técnicos educativos, encarregados de educação) ou ainda da articulação com outros âmbitos institucionais (hospitais, CPCJ, entre outros). As questões não eram totalmente fechadas, havendo algum espaço de abertura para que os entrevistados pudessem introduzir outras questões que considerassem pertinentes para o desenvolvimento do estudo.

Do material recolhido, posteriormente analisado com recurso à técnica de análise de conteúdo, resultaram um conjunto de pontos de vista críticos que se ancoram sobre uma pluralidade de gramáticas justificadoras (Boltanski \& Thévenot, 1991) em relação à controvérsia das formas de regular os comportamentos dos alunos com PHDA - medicação versus terapêuticas convencionais e cognitivas - que tivemos oportunidade de explorar noutros contextos (Feijão \& Freitas, 2014).

Um novo olhar sobre o mesmo material permitiu-nos descobrir outros elementos interessantes, desta vez centrados no problema do reconhecimento e das formas de trabalhar os alunos com PHDA. Com efeito, constatámos que coexistiam uma pluralidade de formas de trabalhar e de reconhecer os alunos com PHDA e 


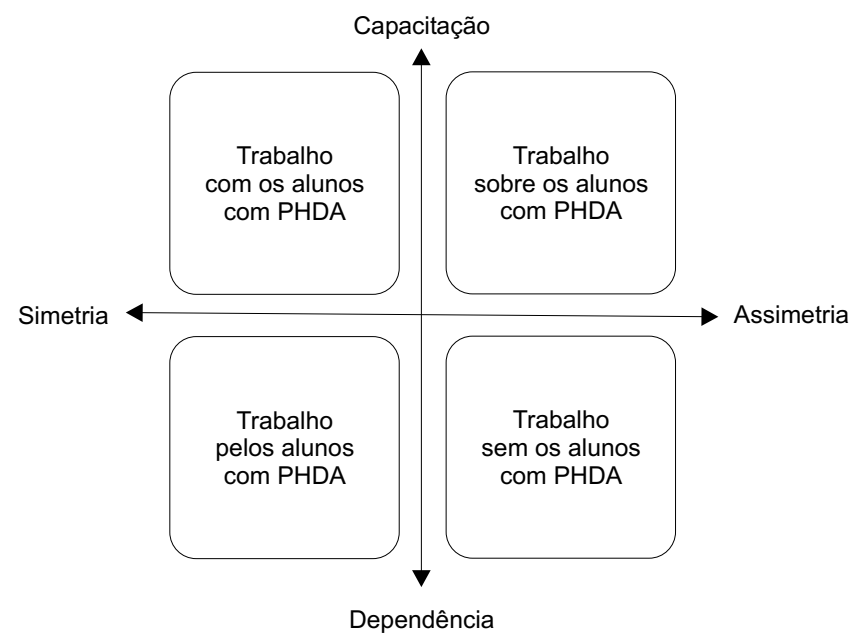

Figura 1 Pluralidade de formas de trabalhar os alunos com PHDA segundo diferentes esquemas de identificação e de relação

Fonte: Adaptado de Laforgue (2009).

que essa pluralidade na ação tem que ver com a existência de diferentes esquemas de identificação e de relação (Laforgue, 2009) da escola e dos seus profissionais face a essa tipologia de alunos.

A matriz apresentada acima cruza dois eixos. O eixo vertical representa o esquema de identificação, que diz respeito à forma como se identificam os alunos com PHDA, considerando-os ora como seres capazes de ter voz e autonomia, ora como seres dependentes e onde a sua subjetividade e autonomia são dificilmente reconhecidas. O eixo horizontal representa o esquema de relação com os alunos com PHDA, podendo a modalidade da relação tomar uma forma de relação simétrica ou assimétrica, ou seja, praticando uma ordenação na horizontal ou procurado estabelecer um critério de hierarquização vertical em relação a esses alunos. Do cruzamento dos dois eixos surgem quatro formas de trabalhar os alunos com PHDA. As instituições contemporâneas são assim híbridas porque albergam uma pluralidade de formas de trabalhar e tratar o outro, categorizando-o de forma ambivalente (Laforgue, 2009). Neste sentido, a matriz que se apresenta acima constitui-se como ponto de partida para a apresentação dos resultados do estudo, que serão apresentados seguidamente. 


\section{Apresentação dos resultados}

Condições, formas e limites do trabalho sobre os alunos com PHDA: olhares dos atores educativos para as políticas e apoios ao ensino especial

O olhar dos atores educativos para as políticas públicas que regulam o trabalho sobre os alunos com necessidades educativas especiais, sejam eles professores do ensino especial, professores do ensino regular ou técnicos de saúde escolar, é indutor de críticas acérrimas. Com efeito, as políticas para o ensino especial são percecionadas não só como demasiado abrangentes, mas também condicionadoras da possibilidade de atuação pelo desinvestimento em recursos humanos especializados para fazer face aos diferentes casos de alunos com necessidades educativas especiais:

Há conjuntos de medidas que não são suficientes para ajudar estes alunos no sentido em que são muito abrangentes, são muito gerais e a escola não tem possibilidade de os ajudar melhor, no sentido em que não há técnicos especializados neste momento para ajudar estes alunos. (Professor do ensino regular, E6)

Mas a dureza das críticas é mais notória junto dos profissionais que trabalham mais de perto com estes alunos, nomeadamente os professores do ensino especial e os técnicos especializados. Desde logo, é apontada a falta de clareza sobre quem é ou não legível para beneficiar dos apoios da equipa de ensino especial: “ A legislação sobre educação especial em Portugal é um pouco controversa. Não temos todos a ideia do que é, nem os mesmos conceitos sobre o que é a elegibilidade, sobre quem é elegível [...]" (Professor do ensino especial, E7). Os técnicos especializados apontam, por um lado, que quem produz estas políticas tem um olhar distante da realidade que revela desconhecimento do que se passa no terreno: "[...] os órgãos superiores, nomeadamente o Ministério, fazem apenas as leis, mas muitas dessas pessoas não conhecem o terreno, nunca lá foram, nem sabem do que se trata" (Técnica psicomotricista, E13). Por outro lado, mostram preocupação com o que esta falta de conhecimento pode trazer na produção das políticas educativas, sobretudo para os públicos-alvo: “[...] muitas vezes a solução encontrada é retirá-los da sala de aula. Às vezes acho que nem sempre é o mais indicado para o aluno porque está a sair do contexto do grupo-turma" (Psicóloga clínica, E12).

Desta forma, o olhar dos profissionais de ensino e dos técnicos em relação às políticas educativas em matéria de ensino especial revela uma crítica a dois princípios de justiça escolar: por um lado, ao modelo industrial (Boltanski \& Thévenot, 1991), assente no paradigma da eficácia escolar, reiterando-se o desinvestimento no financiamento de recursos humanos especializados que garantam o acompanhamento dos casos, 
mas também apontando a falta de consenso em torno da definição dos públicos beneficiários desse acompanhamento; por outro lado, assiste-se a uma crítica ao modelo cívico (Boltanski \& Thévenot, 1991) ancorado no paradigma da escola inclusiva, promovendo a ideia de que a escola deve garantir a igualdade de oportunidades e de tratamento a todos os alunos, não provocando a discriminação dos mesmos e a sua marginalização dentro da instituição escolar.

Integrar na ordem comum e garantir a preservação da singularidade:

o trabalho com e pelos alunos com PHDA

Os professores de ensino especial e os técnicos especializados em saúde escolar lidam com aquilo a que Jean-Paul Payet (2006) chama de uma administração sensível da vulnerabilidade. O reconhecimento do outro como ser vulnerável passa em primeiro lugar pela compreensão do handicap do outro, que é a marca da sua singularidade. Ora, como observámos as políticas públicas de educação especial não deixam claro quem são os elegíveis que vão beneficiar do acompanhamento das equipas e o próprio reconhecimento do aluno hiperativo e/ou com défice de atenção é também gerador de tensões e de falta de consenso entre os profissionais educativos: "somos todos especialistas e depois chega-se à escola e ninguém percebe metade" (Professora do ensino especial, E9).

No início de cada ano letivo, existe uma formação que é dada aos professores de ensino regular para que fiquem sensibilizados em relação às problemáticas dos alunos com necessidades educativas especiais. Todos os professores podem sinalizar os alunos, devendo preencher o formulário que pode ser recolhido junto dos serviços de psicologia e orientação escolar. Quando um professor reporta a sua suspeita, a ocorrência é debatida em Conselho de Turma, sendo posteriormente remetida para a equipa de ensino especial, caso os professores cheguem a acordo sobre avançar com essa sinalização. Os registos nas fichas de referenciação que chegam aos Departamentos de Ensino Especial fazem prova da forma como reina a falta de consenso entre os profissionais de ensino em relação ao aluno com PHDA:

Às vezes as fichas não trazem nada! "Ai, ele é muito distraído e perturba”. Hum, hum e isso significa o quê? Que está a olhar para os pássaros lá fora, que perturba e atira a cadeira ao vizinho ou que perturba porque deixa cair o lápis? (Professora do ensino especial, E8)

A dificuldade de fazer a administração sensível da vulnerabilidade (Payet, 2006), ou seja, de fazerem com que os seus pares compreendam a vulnerabilidade que está associada aos alunos com perturbação de hiperatividade e défice de atenção é 
dificultada também, segundo os profissionais educativos, por uma falta de consenso da parte da comunidade científica, nomeadamente da comunidade médica, em relação à patologia: "Alguns médicos de família, sobretudo os mais velhos, muitos deles não estão alertados, preparados para trabalhar de forma melhor com as crianças" (Professor do ensino especial, E5). São apontadas críticas ao facto da comunidade médica ser demasiado facilitadora no diagnóstico e na forma como gere a questão da PHDA:

Acho que se criou um rótulo muito fácil que de alguma forma é mais fácil de lidar [...] dar um comprimido a uma criança que seja muito agitada [é mais fácil] do que tentar perceber as razões ou todas as dimensões dessa criança e tentar perceber o que se passa [...]. (Professor do ensino especial, E10)

Apesar de reconhecerem que é um diagnóstico difícil, não encontram no uso da medicação a solução, optando por uma terapia de tipo comportamental:

Não é um diagnóstico fácil de fazer porque muitas características, sinais e sintomas da patologia se confundem com sinais e sintomas de outras patologias [...] a comunidade terapêutica tem uma visão mais centrada na criança e em todo o seu comportamento, tendo em conta as condicionantes que poderão estar adjacentes à problemática. (Terapeuta psicomotricista, E13)

Esta falta de entendimento sobre a definição e o tratamento da PHDA torna também difícil o trabalho com as famílias desses alunos. Com efeito, algumas famílias tendem a encarar a PHDA como um estigma, evitando pensar nela a todo o custo: "Há aquelas famílias que acham que não é nada e que as coisas se vão resolver e não ouvem ninguém" (Professor de ensino especial, E7). A ausência de cooperação entre famílias e equipas pedagógicas (professores e técnicos especializados) pode também gerar mal-estar na criança:

Não respeitam a criança, não respeitam a sua condição de crianças ... tendem a julgá-la como alguém que é mal-educado, que não sabe estar, que não se sabe comportar. E muitas delas fazem um uso abusivo do castigo, da punição, de palavras menos próprias e desmotivantes para aquela criança. (Técnica psicomotricista, E13)

São também estas famílias que fazem um uso abusivo da medicação: "[Os pais] percebem que há uma pressão por parte da escola, dos professores de turma [...] voltam a dar e depois deixam de dar, e depois há outros que dizem 'Não, não! Não vamos voltar a dar'" (Psicóloga clínica, E12). Para estes profissionais o uso da medicação não faz sentido sem ser complementado com o uso de intervenção terapêutica: " 
Defendo que a farmacologia neste caso seja abordada como psicofarmacologia, concordo que nalguns casos seja prescrita a medicação, mas sempre em trabalho conjunto com uma intervenção terapêutica" (Terapeuta psicomotricista, E13),

[...] só a farmacologia é um tapar e depois não há estratégias como a terapia, que eu considero fundamental $[\ldots]$ acho que muitas vezes nos encostamos um bocadinho atrás disso $[\ldots]$ achar que os medicamentos fazem milagres [...] a criança toma a medicação e vem logo mais apática nessa manhã. (Psicóloga clínica, E12)

Tanto professores do ensino especial, como técnicos educativos são unânimes quanto ao facto de que a intervenção terapêutica deve acompanhar e complementar a administração de fármacos. $O$ trabalho de intervenção terapêutica é caracterizado pela proximidade aos alunos, nomeadamente através de um envolvimento num regime de familiaridade (Thévenot, 2006) que permite estar próximo dos alunos, atendendo aquilo que os torna singulares, mas sem colonizar essa proximidade e invadir o seu íntimo (Pattaroni, 2007). Estes profissionais reconhecem que não existe um método único e eficaz que consiga ser aplicado. Existem uma pluralidade de estratégias que podem ser adotadas e que permitem minimizar os danos provocados dentro da sala de aula e aumentar o gasto de energias por parte desses alunos. Como refere um professor " [...] para alguns alunos determinadas estratégias funcionam, para outros as mesmas estratégias não funcionam de maneira nenhuma [...] qualquer estratégia é boa desde que resulte [...]" (Professor de ensino especial, E8). As estratégias mais comuns são a “[...] organização do espaço, organização do tempo e organização dos conteúdos [...]" (Professor de ensino especial, E9). A proximidade ao aluno é um aspeto fundamental para melhor dar conta dos comportamentos turbulentos e minimizar os seus efeitos, sendo que "fazer um toque no braço ou um toque na mesa e manter os alunos longe das janelas e portas de forma a que não se distraiam com os colegas e ter apenas o necessário em cima da mesa" (Psicóloga clínica, E12) podem ser formas de envolvimento em proximidade ajustadas a estas situações.

O grande dilema que estes profissionais enfrentam é sobretudo quando este trabalho não é possível, sendo que esta impossibilidade não tem diretamente a ver com os alunos, mas com os professores, sobretudo do ensino regular, que muitas vezes se recusam a trabalhar com estes alunos.

Da hospitalidade hostil na escola: o trabalho sem os alunos com PHDA

Os relatos de três professores do ensino regular dão conta do sofrimento e dos dilemas vividos em sala de aula quando confrontados com situações de interação com 
alunos hiperativos e com défice de atenção: “Às vezes já por cansaço do adulto por chamar uma, duas, três, quatro vezes à atenção acaba por o deixar de parte [...]" (Professor do ensino regular, E3); “[...] quando destabiliza digo-lhe 'vai correr para o intervalo porque aqui estás a incomodar'" (Professor do ensino regular, E4); "muitas vezes eles são colocados fora da sala de aula não digo injustamente porque eles fazem asneiras claro, não é a questão de ser injusto [...] nós não temos formação para isso" (Professor do ensino regular, E5).

Os estudos sociológicos têm revelado que a gestão das salas de aula é considerada como uma das tarefas mais desgastantes do trabalho dos professores e que traz à tona sentimentos de desengrandecimento profissional e de humilhação, pois estas situações são vivenciadas como problemas de competência profissional (Barrère, 2005).

O investimento de forma (Thévenot, 2006), que os professores produzem sobre estes alunos não é indiferente aos sentimentos que manifestam quando confrontados com situações críticas em sala de aula: "[...] parecem mesmo que estão numa realidade tipo à parte [...]" (Professor de ensino regular, E3); “(...) qualquer aluno que se distraia com a menor das facilidades é no geral uma fonte de problemas, digamos assim, problemas para ele próprio e problemas para os outros também [...]" (Professor do ensino regular, E6); “[...] não conseguem estar atentos à aula, são alunos que têm alguma dificuldade em se concentrarem e acompanharem o ritmo da aula [...] acabam por perturbar também o bom funcionamento das aulas" (Professor do ensino regular, E1); "têm mau comportamento, são agressivos, são mal educados, insultam-se uns aos outros [...]" (Professor do ensino regular, E5); "estes meninos têm uma tendência para serem marginais e para perturbarem muito a escola e faltarem e terem comportamentos de risco [...]" (Professor de ensino regular, E2).

Estes julgamentos depreciativos associados ao sofrimento vivido no confronto com as situações, levam os professores do ensino regular, a recorrerem a estratégias de evitamento quando são confrontados com alunos com perturbações de hiperatividade e/ ou défice de atenção. Estas estratégias de evitamento passam sobretudo pela expulsão da sala de aula, pela exclusão e encaminhamento para os gabinetes dos técnicos escolares e departamentos de ensino especial. Atendamos ao relato deste professor de ensino regular:

Eles não são os únicos alunos na turma e nós não podemos estar constantemente a chamá-los à atenção não podemos passar noventa minutos a chamar à atenção um único aluno [...] levam-nos obrigatoriamente a alterar e a diversificar as estratégias dentro da sala de aula, nem sempre nos é possível fazer isso, primeiro porque precisamos de expor um determinado assunto que pode demorar entre dez a vinte minutos e para alguns alunos já é difícil tomar atenção a vinte minutos depois aquilo que eles 
fazem ... como não tomaram atenção não conseguem fazer e nós nem sempre conseguimos explicar-lhes só a eles, de maneira a que eles percebam, porque estão lá os outros todos também [...]. (Professor do ensino regular, E6)

Está presente neste relato uma tensão entre dois princípios de justiça, que para este professor, são difíceis de compatibilizar: o princípio da inclusão e o princípio da eficácia. Por um lado, é preciso garantir o sucesso da turma como coletivo; por outro lado, é preciso chegar às dificuldades de cada um, reconhecendo as suas singularidades e dificuldades de aprendizagem e delineando estratégias pedagógicas desenhadas à medida de cada aluno. Tecer um compromisso entre estes dois princípios de justiça é uma tarefa quase impossível. A solução parece ser então a de reencaminhar os alunos para aqueles que têm competência para proceder ao seu tratamento institucional:

[...] eles precisam que nós estejamos ali junto deles, sentados a ajudá-los e dentro da sala de aula e nós temos mais vinte e seis ou vinte e sete alunos, portanto não podemos estar única e exclusivamente com aqueles alunos [...] e eu quando digo retirá-los é saírem da sala de aula onde está a turma toda e irem para um gabinete de trabalho trabalhar com o técnico ou com um qualquer professor, mesmo que seja a fazer o mesmo trabalho da turma. (Professor do ensino regular, E6)

Para os professores do ensino regular, os conteúdos programáticos têm de ser adaptados às necessidades especiais destes alunos e são fortemente defensores de que é uma necessidade estes alunos serem acompanhados por profissionais habilitados para fazer a intervenção terapêutica. Alguns professores também não creem no poder da intervenção farmacológica porque "tornam os alunos apáticos" (Professor do ensino regular, E1), sendo que também a hipoatividade por parte do aluno é considerada como um comportamento a-escolar. Contudo, outros professores aplaudem o uso da medicação:

[...] é ótimo que eles tomem a medicação porque eles próprios em geral se sentem muito melhor [...] são capazes de aprender e sabem que são capazes de fazer as mesmas coisas tal e qual os outros e por outro lado, também se sentem incapazes de o fazer por si próprios e a medicação vem completamente alterar a sua forma de estar dentro da sala de aula e ajuda-os também a passarem um patamar mais acima e a ultrapassar dificuldades que eles tinham e que lhes permite alcançar metas, alcançar objetivos que de outra forma não seriam capazes de o fazer. (Professor do ensino regular, E3)

Os professores defensores do uso de fármacos, ancoram-se numa gramática industrial (Boltanski \& Thévenot, 1991) para justificar a ideia de que o uso da medicação 
promove o aumento do rendimento escolar, da autoconfiança do aluno e do bem-estar do professor e da turma.

Os alunos com hiperatividade e défice de atenção são assim vítimas de uma exclusão no interior da escola (Bourdieu \& Champagne, 1992). O paradoxo apresentado por Jacques Derrida quando se interroga se é possível praticar uma hospitalidade incondicional, ilustra bem a situação vivenciada por estes alunos: “Oferecemos hospitalidade na condição de que o outro obedeça às nossas regras, ao nosso modo de vida, até mesmo à nossa linguagem, à nossa cultura, ao nosso sistema político" (Derrida, 2004, p. 138). De um lado é-se hospitaleiro, incluindo o outro e respeitando os seus direitos, mas por outro lado é-se hostil impondo normas de aceitação, representando-o como igual e negando a sua diferença.

\section{Considerações finais: sobre a dificuldade de compor uma inclusão eficaz para os alunos com PHDA}

A escola contemporânea revela hoje uma dificuldade em encontrar um compromisso entre dois princípios de justiça: a inclusão e a eficácia. A democratização contribuiu para a integração de todos na escola, mas não concretizou o princípio da inclusão, que permanece ainda um slogan por concretizar (Dubet, 2003; 2004; 2007; Sanches \& Teodoro, 2006). Alguns sociólogos têm denunciado a existência de uma exclusão fabricada subtilmente no interior das escolas (Bourdieu \& Champagne, 1992; Dubet, 2003). Esta exclusão parece ser uma condição para a fabricação e concretização da eficácia escolar.

Através do estudo do trabalho de intervenção com alunos com necessidades educativas especiais, sobretudo daqueles com Perturbação de Hiperatividade e Défice de Atenção, denotámos a coexistência de uma pluralidade de formas de trabalhar os alunos com PHDA: o trabalho sobre os alunos com PHDA, o trabalho com os alunos com PHDA, o trabalho pelos os alunos com PHDA e o trabalho sem os alunos com PHDA. Esta forma de encarar os mais vulneráveis e o próprio investimento de forma da vulnerabilidade (Thévenot, 2006) não têm o mesmo eco junto de todos os atores escolares.

Por um lado, assistimos ao trabalho pelos alunos com PHDA e ao trabalho com os alunos com PHDA levado a cabo pelos professores do ensino especial e pelos técnicos educativos que são sensíveis ao rótulo do aluno com necessidades educativas especiais e que desenvolvem estratégias de trabalho, procurando não anular as diferenças, respeitar a subjetividade e integrar estes alunos na ordem comum. Por outro lado, o trabalho sobre os alunos com PHDA e o trabalho sem os alunos com PHDA que é investido quer pelos responsáveis pelo desenho das políticas públicas de 
educação especial, quer pelos professores de ensino regular, que não estando sensibilizados, quer pela distância em relação à realidade, quer pela pouca formação na área, tendem a anular a diferença, a não reconhecer a subjetividade destes alunos e a reduzi-los a uma condição de mesmidade.

Como defende Skliar (2003, p. 39) "não temos, nunca, compreendido o outro. Temos, sim, o massacrado, assimilado, ignorado, excluído e incluído, e, por isso, para negar a nossa invenção do outro, preferimos hoje afirmar que estamos frente a frente com um novo sujeito". Este novo sujeito lida com uma situação ambivalente que as instituições como a escola o fazem experienciar e que é descrita por Jean-Paul Payet (2006): de um lado, um sentimento de controlo e normalização, de colonização pela proximidade e redução a uma condição de mesmo; do outro lado, uma procura pelo reconhecimento da sua subjetividade e de exaltação da sua diferença.

\section{Notas}

1. Por decisão pessoal, os autores do texto escrevem segundo o novo acordo ortográfico.

\section{Referências}

Aranha, M. S. (2008). Paradigmas da relação da sociedade com as pessoas com deficiência. Marília: UNESP.

Associação Portuguesa da Criança Hiperativa (s/d). A associação. Retrieved from https://apdch.net/

Barrère, A. (2005). O trabalho em equipa e o risco de gestão das turmas. Análise Social, XL(176), 619-631.

Boltanski, L., \& Thévenot, L. (1991). On justification: Economies of worth. Princeton: Princeton University Presses.

Bourdieu, P., \& Champagne, P. (1992). Os excluídos do interior. In M. A. Nogueira, \& A. Catani (1998) (Eds.), Pierre Bourdieu: Escritos de educação (pp. 20-217). Petropólis: Editora Vozes.

Breviglieri, M. (2009). L'insupportable: L'excès de proximité, l'atteint à l'autonomie et le sentiment de violation du privé. In D. Trom, C. Lafaye, \& M. Breviglieri (Eds.), Compétences critiques et sens de la justice (pp. 125-149), Paris: Economica.

Costa, C., et al. (2010). Perturbação de hiperatividade e défice de atenção: Revisão teórica e áreas de intervenção. Comunicação apresentada no VIII Simpósio Internacional de Investigação e Psicologia, Braga, Portugal.

Derrida, J. (2004). Adeus a Emmanuel Lévinas. São Paulo: Perspetiva. 
Dionísio, B., Resende, J., \& Caetano, P. (2014). Das experiências de (des)qualificação das pessoas à precariedade dos laços entre os seres que habitam o mundo escolar. Revista Dilemmas, 7(1), 11-38.

Dubet, F. (2002). Le déclin de l'institution. Paris: Seuil.

Dubet, F. (2003). Escola e exclusão. Cadernos de Pesquisa, (119), 29-45.

Dubet, F. (2004). O que é uma escola justa?. Cadernos de Pesquisa, (123), 539-555.

Dubet, F. (2007). Démocratisation et justice scolaire. In S. Paugam (Ed.), Repenser la solidarité (pp. 111-124). Paris: PUF.

Dubet, F., et al. (2013). Pourquoi moi? L'expérience des discriminations. Paris: Seuil.

Feijão, J. (2015). Do imperativo da inclusão eficaz: As políticas de educação prioritária e as suas gramáticas de justiça escolar. Comunicação apresentada na Graduate Conference of Doctoral Studies Pedro Hispano, FCSH-UNL, Lisboa, Portugal.

Feijão, J., \& Freitas, N. (2014). A construção escolar da hiperatividade: Controvérsias acerca do trabalho de diagnóstico e intervenção sobre jovens com PHDA em escolas portuguesas. Revista Ambivalências, 2(4), 35-65.

Giuliani, F., et al. (2008). La reconnaissance des personnes: Ce dont les institutions ce sont capables. In J.-P. Payet, \& A. Battegay (Eds.), La reconnaissance à l'épreuve: Explorations socio-anthropologiques (pp. 113-122). Lille: Presses Universitaires du Septentrion.

Honneth, A. (2005). L'invisibilité: Sur l'épistémologie de la reconnaissance. Réseaux, (129/130), 39-57.

Laforgue, D. (2009). Pour une sociologie des institutions publiques contemporaines. Socio-logos: Revue de l'Association Française de Sociologie, (4), s/p. Retrieved from http:/ / socio-logos.revues.org/ 2317

Lourenço, M. I. (2009). Hiperatividade e défice de atenção em meio escola (Dissertação de mestrado). Universidade Técnica de Lisboa, Faculdade de Motricidade Humana, Lisboa, Portugal.

Millet, M., \& Thin, D. (2003). Une déscolarisation encadrée: Le traitement institutionnel du désordre scolaire dans les dispositifs-relais. Actes de la Recherche en Sciences Sociales, France, 149, 32-41.

Pattaroni, L. (2007). Le sujet en individu: La promesse de l'autonomie du travail sociale au risque d'une colonisation par le proche. In F. Cantelli, \& J. L. Genard (Orgs.), Action publique et subjectivité (pp. 203-218), Paris: LJGD.

Payet, J.-P. (2006). Le label sensible: Entre surcontrôle et reconnaissance. In M. Peroni, \& J. Roux (Eds.), Sensibiliser: La sociologie dans le vif du monde (pp. 51-57). La Tour d'Aigues: L'Aube.

Payet, J.-P., et al. (2008). La voix des acteurs faibles: De l'indignité à la reconnaissance. Rennes: PUR.

Pereira, M. J. (2008). Atitude estratégica do professor face à hiperatividade (Dissertação de mestrado). Universidade Católica Portuguesa, Faculdade de Ciências Sociais, Portugal.

Resende, J., \& Gouveia, L. (2013). As artes de fazer o comum nos estabelecimentos de ensino: Outras aberturas sociológicas sobre os mundos escolares. Fórum Sociológico, (23), 97-106. 
Sanches, I., \& Teodoro, A. (2006). Da integração à inclusão escolar: Cruzando perspetivas e conceitos. Revista Lusófona de Educação, 8(8), 63-83.

Skliar, C. (2003). A educação e a pergunta pelos outros: Diferença, alteridade, diversidade e os "outros". Ponto de Vista: Revista de Educação e Processos Inclusivos, (5), 37-49.

Thévenot, L. (2006). L'action au pluriel: Sociologie des régimes d'engagement. Paris: La Découverte.

João Feijão. Universidade NOVA de Lisboa, Faculdade de Ciências Sociais e Humanas, Centro Interdisciplinar de Ciências Sociais (CICS.NOVA).

Nélia Freitas. Universidade NOVA de Lisboa, Faculdade de Ciências Sociais e Humanas (NOVA FCSH).

Data de submissão: 01/10/2017 | Data de aceitação: 22/11/2017 